\title{
BMJ Open Availability and readiness to provide sexually transmitted infections and HIV testing and counselling services in Nepal: evidence from comprehensive health facility survey
}

Kiran Acharya (D , , Rajshree Thapa, ${ }^{2}$ Navaraj Bhattarai, ${ }^{3}$ Kiran Bam, ${ }^{4}$ Bhagawan Shrestha ${ }^{4}$

To cite: Acharya K, Thapa R, Bhattarai N, et al. Availability and readiness to provide sexually transmitted infections and HIV testing and counselling services in Nepal: evidence from comprehensive health facility survey. BMJ Open 2020;10:e040918. doi:10.1136/ bmjopen-2020-040918

- Prepublication history and supplemental material for this paper is available online. To view these files, please visit the journal online (http://dx.doi. org/10.1136/bmjopen-2020040918).

Received 26 May 2020 Revised 17 November 2020 Accepted 23 November 2020

Check for updates

(c) Author(s) (or their employer(s)) 2020. Re-use permitted under CC BY-NC. No commercial re-use. See rights and permissions. Published by BMJ.

${ }^{1}$ New ERA, Kalopul, Kathmandu, Nepal

${ }^{2}$ Department of Medicine,

Monash University, Melbourne, Victoria, Australia

${ }^{3}$ Nepal Public Health Research and Development Center,

Kathmandu, Nepal

${ }^{4}$ Public Health Professional, Kathmandu, Nepal

Correspondence to

Mr Kiran Acharya;

acharya.kiran1@gmail.com

\section{ABSTRACT}

Objective We assessed the availability and readiness of health facilities to provide sexually transmitted infections (STI) and HIV testing and counselling (HTC) services in Nepal.

Design This was a cross-sectional study.

Setting We used data from the most recent nationally representative Nepal Health Facility Survey (NHFS) 2015. A total of 963 health facilities were surveyed with $97 \%$ response rate.

Primary and secondary outcome measures The primary outcome of this study was to assess the availability and readiness of health facilities to provide STI and HTC services using the WHO Service Availability and Readiness Assessment (SARA) manual.

Results Nearly three-fourths $(73.8 \%)$ and less than one-tenth $(5.9 \%)$ of health facilities reported providing STI and HTC services, respectively. The mean readiness score of STI and HTC services was $26.2 \%$ and $68.9 \%$, respectively. The readiness scores varied significantly according to the managing authority (private vs public) for both STI and HTC services. Interestingly, health facilities with external supervision had better service readiness scores for STI services that were almost four points higher than compared with those facilities with no external supervision. Regarding HTC services, service readiness was lower at private hospitals (32.9 points lower) compared to government hospitals. Unlike STI services, the readiness of facilities to provide HTC services was higher (4.8 point higher) at facilities which performed quality assurance.

Conclusion The facility readiness for HTC service is higher than that for STI services. There are persistent gaps in staff, guidelines and medicine and commodities across both services. Government of Nepal should focus on ensuring constant supervision and quality assurance, as these were among the determining factors for facility readiness.

\section{INTRODUCTION}

HIV continues to be a global public health issue though significant progress and achievement have been made through community

\section{Strengths and limitations of this study}

- This is the first study using nationally representative survey data to identify factors associated with readiness to provide sexually transmitted infection (STI) and HIV testing and counselling (HTC) services in Nepal.

- This study accurately reflects the baseline situation regarding availability and readiness to provide STI and HTC service in Nepal.

- The findings were adjusted for clustering effect and weighted to correct for complex sampling procedure and non-response and disproportionate sampling, respectively.

- This study provides the evidences using the standard WHO Service Availability and Readiness Assessment (SARA) manual.

- The causal relationship could not be established from the current study.

engagement, decentralisation of HIV testing and treatment services and implementation of innovative approaches. ${ }^{1}$ Preventing sexually transmitted infection (STI) is one of the strategies to reduce new HIV infections so programmes recommend STI screening as a part of HIV services. ${ }^{2}$ Despite these gains, HIV remains a global public health challenge with gaps to attain $90-90-90$ by 2020 and ending AIDS by 2030. Of 37.9 million estimated people living with HIV (PLHIV), nearly one in five PLHIV do not know their HIV status, one-third of all PLHIV are not on antiretroviral therapy, and half had unsuppressed viral loads in 2018. ${ }^{1}$ However, these numbers are disproportionately distributed with varied epidemic scenarios across the regions and nations so tailored interventions are paramount to curb the HIV epidemic. 
Nepal is facing a concentrated HIV epidemic with more than $5 \%$ prevalence among selected key populations such as people who inject drugs, male sex workers and transgender people. In 2018, there are approximately 29944 PLHIV in Nepal, with an estimated overall adult (15-49 years) HIV prevalence of $0.14 \% .^{3}$ Of the total estimated PLHIV, one-third of people are unaware of their status as of July 2019, which is mainly because of low access to HIV testing services and reluctance to access HIV testing services either due of lack of population friendly services or gender sensitive services, and fear of stigma and discrimination. ${ }^{4}$ STIs are a growing problem in Nepal affecting more women than men. A total of 140 559 cases of STIs were reported in Nepal in 2017. Syphilis prevalence among key populations is reported to be around 2\%. ${ }^{3}$ The National HIV Testing and Treatment Guideline 2017 states that screening, diagnosis and treatment of STI should be part of the HIV programmes and all adolescents and adults should be offered STI services while receiving HIV services. STI services are also part of basic health services and HIV testing is the entry for HIV services, primarily provided through government, nongovernmental organisation (NGO)-run facilities and a few private clinics. HIV testing services are free of cost through 175 HIV testing centres including 137 government run centres. ${ }^{3}$ Similarly, HIV testing services have been decentralised through provision of HIV screening at the community level including oral fluid-based HIV self-testing. However, HIV testing coverage among key populations in Nepal is still low with just $50 \%{ }^{5}{ }^{5}$ The recent Nepal Demographic Health Survey 2016 reports only $20.5 \%$ men and $10.8 \%$ women ages $15-49$ years have ever tested for HIV. ${ }^{6}$ STI symptoms were reported among $15 \%$ of women and $2 \%$ of men who had ever had sexual intercourse. ${ }^{6}$ In the current context, integration and scale-up of HIV testing services are required to minimise access related barriers, bring services closer to the communities, provide early detection of HIV cases and link them for treatment, care and support services. ${ }^{7}$ In Nepal, STIs diagnosis and treatment services are currently provided through government- and NGO-run sites. In Nepal, based on the available resources, syndromic diagnostic approach and laboratory testing are recommended. ${ }^{89}$ HIV and STI counselling and testing are provided up to the health post (HP) level and by both public and private sectors in Nepal. ${ }^{10}$ STI services are provided as a part of maternal and child health and family planning (FP) services in Nepal. ${ }^{9}$

There are different factors that determine the utilisation of counselling and testing services for STIs and HIV. Both the demand and supply side factors affect counselling and testing related to STI and HIV. ${ }^{511}$ However, most of the research to date have focused on examining the knowledge and key population's behavioural factors in relation to HIV testing and counselling (HTC) services. ${ }^{512} 13$ The National HIV Strategic Plan 2016-2021 has committed to fast-tracking the HIV response to reach 90-90-90 targets by 2020 and ending AIDS as a public health threat by 2030. Similarly, the Government of Nepal has endorsed the sustainable development goals (SDGs) and ending the AIDS epidemic as public health threat by 2030. Among the supply side factors, service availability, location, facilities, test kits availability and service organisations were reported as potential determinants to improve HTC access among specific key populations. ${ }^{12}$ But there is need for country level information on availability and readiness to assess country capacity in delivering quality HTC services. Service availability and readiness reflect the system level willingness and preparedness to provide quality services. ${ }^{14}$ Globally, investigators have assessed service availability and readiness for maternal health, child health services and FP services using the Service Provision Assessment (SPA) and Service Availability and Readiness Assessment (SARA); however, information on service availability for HIV or STI remains less documented.

Thus, to fulfil the supply side information gap, this analysis has been conducted to assess and inform the health facility service availability and readiness to provide STI and HTC service in Nepal. In our knowledge, related analyses have not been conducted earlier and the findings are critical to inform gaps to guide resource allocation and service provisions in low- income countries such as Nepal.

\section{METHODS}

\section{Data source and sampling procedure}

We used data from the Nepal Health Facility Survey (NHFS) conducted in 2015 that combines the components of the United States Agency for International Development (USAID)-supported SPA of the Demographic and Health Survey (DHS) programme, WHO's SARA, United Nations Population Fund's (UNFPA) Facility Assessment for Reproductive Health Commodities and Services and the Nepal specific Service Tracking Survey. The comprehensive nationally representative cross-sectional survey of health facilities provides information on formal sector health facilities regarding the availability of basic and essential healthcare services and the readiness of health facilities to provide quality health services. The report is published elsewhere. ${ }^{15}$

The survey sampling was based on a master list of 4719 formal-sector health facilities in Nepal, obtained from the Ministry of Health and Population. This was used as the sampling frame and out of them a total of 1000 facilities were selected for the survey. Briefly, the study sample included all non-specialised government hospitals, all private hospitals with 100 or more inpatient beds and all primary health care centres (PHCCs). The remainder of the sample consisted of HPs, private hospitals with at least 15 beds but fewer than 100 beds, stand-alone HTC sites and Urban Health Centres (UHCs). The sample of the 2015 NHFS was a stratified random sample of health facilities selected with equal probability systematic sampling with the sample allocation. Stratification was achieved by 
separating by the type of facility/public-private health facility within each domain. The private hospitals were further stratified by the number of beds within domain: $100+$ beds and less than 100 beds, where applicable. The sample allocation features a complex allocation accounting for different factors. Eight sampled facilities turned out to be duplicates during the implementation of the survey, resulting in an effective sample size of 992 facilities. A total of 963 health facilities were successfully surveyed with $97 \%$ response rate. More detail on the methodology used in this survey can be found in the report published elsewhere. ${ }^{15}$

\section{Data collection}

The implementation of field work took place from April to November 2015. New ERA, a local research firm in Kathmandu, implemented the survey with technical assistance from USAID supported DHS Program (ICF). The UK Department for International Development provided funding for the local costs of the implementation through the Nepal Health Sector Support Program. Trained staff with medical backgrounds were mobilised for the survey. Eight quality assurance officers and the core survey management team monitored the data collection throughout the period. Out of five main types of data collection instruments in NHFS, we have used two types of instruments in our study (Facility Inventory Questionnaire and Health Provider Questionnaire). The information for these two instruments was collected from knowledgeable informants at the facility to determine whether a facility is ready to provide services at acceptable standards. ${ }^{15}$ We used the Facility Inventory Questionnaire to assess staffing levels and support systems for general management and quality assurance. Similarly, a Health Provider Questionnaire was used to assess the status of training received. The rest of the questionnaires used in the survey are related to antenatal care (ANC), FP, curative services of sick children like observations and health facility operation and management committee/health development committee which is beyond our scope of study. The questionnaires/tools used in the survey were harmonised from the standard SPA and SARA tools used worldwide. ${ }^{16}$ The online version of all the questionnaires is published elsewhere. ${ }^{15}$ The specific questionnaire taken for the analysis for this study in particular, is presented in the online supplemental table 1 .

\section{Unit of analysis and study variables}

Based on the indicators on the WHO SARA manual, ${ }^{17}$ service availability refers to facilities offering STI services and facilities with HIV testing systems. STI service is defined as "providers in the facility diagnose STIs or prescribe treatment for STIs or both' and HIV testing service is defined as 'facility reports conducting HIV testing in the facility or else in an external testing site and having an agreement with that external site that test results will be returned to the facility'.
Facility readiness was defined as the willingness or state of the health facility to provide STI and HTC services. This was analysed by the availability of essential equipment and supplies for a specific service in a location reasonably accessible when providing that service; the availability of staff with recent training relevant to the service, as well as service guidelines; the availability of medicines and commodities; and laboratory capacity for tests related to the service. Further, based on the national guidelines on case management of STI, ${ }^{9}$ we further assessed the availability of recommended drugs like azithromycin, doxycycline and penicillin in STI services though not mentioned in the WHO SARA manual. For readiness we were strict to follow the SARA manual, did not include those drugs for the readiness score. The service readiness, however, is described by the tracer items of following domains (table 1).

Other covariates used in the study are facility type, managing authority (public/private), ecological region (mountain, hill and terai) and province (provinces 1-7). The private facilities under the managing authority include: private not-for-profit: NGOs, private for profit organisations and mission/faith organisations. Facility type is categorised as government hospitals (district, zonal and above hospitals), private hospitals (most are managed for profit), peripheral facilities (PHCCs/HPs/UHCs) and standalone HTCs. All standalone HTC facilities are operated by NGOs/private not-for-profit agencies. Other covariates include facility level variables such as: external supervision in the facility in the last 4 months (occurred/ not occurred), monthly management meeting conducted (never/ sometimes/regular), client opinion (reviewed/ not reviewed) and quality assurance (performed/not performed). The selection of these variables was based on the published literature. The urban-rural distribution was not available in the openly available datasets but we have classified them using the global positioning system (GPS) location ${ }^{18}$ available on the request from the DHS programme.

\section{Statistical analysis}

The composite readiness score of STI and HTC service is the outcome variable and it is calculated from the availability of tracer items in each domain mentioned above (three domains for STI and four domains for HTC) using weighted additive procedure. This procedure involves assigning equal weights to each domain and adjusting for the "variation in the number of indicators within each domain so that the weight of the indicator is inversely proportional to the number of indicators in the domain'. ${ }^{19-21}$ For instance, to make the score of $0 \%-100 \%$, each domain was accounted for $33.3 \%(100 / 3)$ of the index for STI services while each domain was accounted for 25\% (100/4) for HTC services. The percentage for each indicator within the domain was equal to $33.3 \%$ for STI services care and 25\% for HTC services divided by the number of indicators in that domain. The summary of the measurement procedure of the readiness score 
Table 1 Tracer items of each domain of sexually transmitted infection and HIV testing and counselling services

\begin{tabular}{lll}
\hline Domain* $^{*}$ & STI service & HTC service \\
\hline Staff and guidelines & Guidelines for diagnosis and treatment of & Guidelines on HTC \\
& STIs & Staff trained on HTC \\
& Staff trained on STI, diagnosis and & \\
& treatment & \\
Equipment & Not applicable & Visual and auditory privacy \\
Diagnostics & Syphilis rapid test & HIV diagnostic capacity $†$ \\
Medicines and commodities & Condoms & Condoms \\
& Metronidazole cap/tab & \\
& Ciprofloxacin cap/tab (not found in 2015 & \\
& NHFS), cefixime cap/tab is used instead & \\
& Ceftriaxone injection & \\
\hline
\end{tabular}

*The WHO Service Availability and Readiness Assessment manual was used to guide the selection of service specific domains and service readiness is defined by important supportive items given in specific services.

†HIV diagnostic capacity was defined as facility reports conducting HIV testing at the facility and had at least one unexpired Determine, at least one unexpired Uni-Gold and at least one unexpired Stat-Pak HIV rapid diagnostic test kit available somewhere in the facility on the day of the survey, or else facility had ELISA testing capacity or other HIV testing capacity observed in the facility on the day of the survey. HTC, HIV Testing and Counselling; NHFS, Nepal Health Facility Survey; STI, Sexually Transmitted Infection.

is given in the online supplemental table 2. Percentage distribution of facilities, readiness score of service readiness and specific domain for both services were calculated. Bivariate and multivariate linear regression analysis was used to assess the relationship between covariates and the outcome variable. All covariates were tested for collinearity before fitting the model. Since facility types and managing authority were highly correlated, we dropped the managing authority from the model and included all other variables. $\mathrm{P}<0.05$ was considered statistically significant in the analysis. Since the 2015 NHFS sample was a stratified sample, sampling weights were calculated based on sampling probabilities separately for each sampling stratum. To ensure the actual representation of the survey results and to provide unbiased estimates of the parameters, we have applied the sampling weights. Further, complex sample design has been taken into account to adjust standard errors that accompany the properly weighted estimates. This was done using 'svy' command in STATA V.15.0 (Stata Corp, College Station Texas, USA).

\section{Patient and public involvement statement}

Patient and public were not involved in this study.

\section{RESULTS}

\section{Service availability}

Out of 963 facilities interviewed, 710 (73.8\%) reported to provide STI service and 57 (5.9\%) reported to provide HTC service during the day of assessment and therefore were included in the analysis of the current study (table 2).

\section{General characteristics}

STI service

More than $80 \%$ of the facilities were peripheral health facilities (PHCCs, UHCs and HPs; table 2). The distribution of the facilities in rural and urban was $44.1 \%$ and $55.9 \%$, respectively. Almost $88 \%$ of facilities were publicly owned and $65.2 \%$ of health facilities reported receiving external supervision in the last 4 months. Interestingly, only $10.5 \%$ of facilities had reviewed the client opinion and had performed quality assurance.

\section{HTC services}

Nearly one-third $(30.6 \%)$ of the facilities providing HTC services were private hospitals followed by standalone HTC sites (27.4\%) and government hospitals (24.8\%). Most of the facilities offering HTC services were located in the urban areas $(94.9 \%)$. More facilities were managed by the private sector and regularly conducted monthly management meetings within the facility. On contrary, peripheral facilities had reviewed the client opinion and had performed quality assurance (table 2 ).

Availability of important supportive items for STI and HTC services Less than $10 \%$ of facilities offering STI services had a staff trained $(8.4 \%)$ in STI diagnosis and treatment and had guidelines $(8.1 \%)$ for diagnosis and treatment of STIs. Similarly, $15.9 \%$ had syphilis rapid diagnostic test kits available on the day of visit. Majority of facilities providing STI services had condoms on the day of the assessment. As for medicines to treat STIs, most facilities offering STI services had metronidazole $(95.5 \%)$. However, less than one in six facilities had cefixime capsule/tablet $(15.8 \%)$ and injectable ceftriaxone $(10.9 \%)$. Around one in three $(35 \%)$ health facilities had doxycycline and less than one in five facilities had azithromycin (19.2\%) (data not shown). Only, $3 \%$ of health facilities had penicillin injection. Further, nearly two-fifth of these facilities have a staff trained in HTC (38.8\%) and guidelines onHTC (34.1\%). Almost all facilities (96\%) with an HTC service had visual and auditory privacy equipment, $80.8 \%$ had HIV test 
Table 2 Percentage distribution of the facilities for specific services according to background characteristics

\begin{tabular}{lcc}
\hline Variable & $\begin{array}{l}\text { STI services } \\
\text { N (\%) }\end{array}$ & $\begin{array}{l}\text { HTC services } \\
\text { N (\%) }\end{array}$ \\
\hline Total & 710 & 57 \\
Facility type & &
\end{tabular}

\begin{tabular}{|c|c|c|}
\hline Government hospitals & $21(3.0)$ & $14(24.8)$ \\
\hline Private hospitals & $65(9.1)$ & $17(30.6)$ \\
\hline Peripheral facilities & $605(85.2)$ & $10(17.2)$ \\
\hline Standalone HTC & $19(2.7)$ & $16(27.4)$ \\
\hline \multicolumn{3}{|l|}{ Managing authority } \\
\hline Public & $627(88.2)$ & $24(42.0)$ \\
\hline Private & $84(11.8)$ & $33(58.0)$ \\
\hline \multicolumn{3}{|l|}{ Location of facility } \\
\hline Rural & $313(44.1)$ & $3(5.1)$ \\
\hline Urban & $397(55.9)$ & 54 (94.9) \\
\hline \multicolumn{3}{|l|}{ Ecological region } \\
\hline Mountain & $73(10.3)$ & $3(4.7)$ \\
\hline Hill & $392(55.2)$ & $26(46.5)$ \\
\hline Terai & 245 (34.5) & $28(48.8)$ \\
\hline \multicolumn{3}{|l|}{ Province } \\
\hline Province 1 & $118(16.7)$ & $5(8.9)$ \\
\hline Province 2 & $117(16.5)$ & $11(19.9)$ \\
\hline Province 3 & $158(22.3)$ & $17(29.2)$ \\
\hline Province 4 & $90(12.7)$ & $7(12.4)$ \\
\hline Province 5 & $105(14.8)$ & $9(16.2)$ \\
\hline Province 6 & $47(6.6)$ & $2(4.0)$ \\
\hline Province 7 & $74(10.4)$ & $5(9.3)$ \\
\hline \multicolumn{3}{|l|}{$\begin{array}{l}\text { External supervision in the } \\
\text { facility in last } 4 \text { months }\end{array}$} \\
\hline Occurred & $463(65.2)$ & $41(71.5)$ \\
\hline Not occurred & $247(34.8)$ & $16(28.6)$ \\
\hline \multicolumn{3}{|l|}{$\begin{array}{l}\text { Monthly management } \\
\text { meeting conducted }\end{array}$} \\
\hline Never & $132(18.6)$ & $3(5.8)$ \\
\hline Sometimes & $100(14.1)$ & $5(9.6)$ \\
\hline Regular & $478(67.3)$ & 48 (84.6) \\
\hline \multicolumn{3}{|l|}{ Client opinion } \\
\hline Reviewed & $75(10.5)$ & $23(40.5)$ \\
\hline Not reviewed & $636(89.5)$ & $34(59.5)$ \\
\hline \multicolumn{3}{|l|}{ Quality assurance } \\
\hline Performed & $143(20.1)$ & $15(25.7)$ \\
\hline Not performed & 568 (79.9) & $42(74.3)$ \\
\hline
\end{tabular}

HTC, HIV Testing and Counselling; STI, Sexually Transmitted Infection.

kits available and $61.2 \%$ had condoms on the day of the assessment (table 3 ).

\section{Facility readiness}

Facility readiness to provide STI and HTC services

The readiness score of the three domains and the overall index of facility readiness to provide STI service are presented in figure 1 . The mean readiness score of STI
Table 3 Indicators of readiness to provide sexually transmitted infection and HIV testing and counselling services

\begin{tabular}{|c|c|}
\hline Indicators & $\begin{array}{l}\text { Total } \\
\mathrm{n}(\%) \text { of facilities in } \\
\text { which indicator is } \\
\text { available }\end{array}$ \\
\hline \multicolumn{2}{|l|}{ STI services $(n=710)$} \\
\hline \multicolumn{2}{|l|}{ Staff and guidelines } \\
\hline $\begin{array}{l}\text { Guidelines for diagnosis and treatment } \\
\text { of STIs }\end{array}$ & $58(8.1)$ \\
\hline $\begin{array}{l}\text { Staff trained in STI diagnosis and } \\
\text { treatment }\end{array}$ & $59(8.4)$ \\
\hline \multicolumn{2}{|l|}{ Diagnostics } \\
\hline Syphilis rapid test & $113(15.9)$ \\
\hline \multicolumn{2}{|l|}{ Medicines and commodities } \\
\hline Condoms & $683(96.2)$ \\
\hline Metronidazole cap/tab & $678(95.5)$ \\
\hline Cifixime cap/tab & $112(15.8)$ \\
\hline Ceftriaxone injection & 77 (10.9) \\
\hline \multicolumn{2}{|l|}{ HTC service $(n=57)$} \\
\hline \multicolumn{2}{|l|}{ Staff and guidelines } \\
\hline Guidelines on HTC & $19(34.1)$ \\
\hline Staff trained in HTC & $22(38.8)$ \\
\hline \multicolumn{2}{|l|}{ Equipment } \\
\hline Visual and auditory privacy & $55(96.3)$ \\
\hline \multicolumn{2}{|l|}{ Diagnostics } \\
\hline HIV diagnostic capacity & $46(80.8)$ \\
\hline \multicolumn{2}{|l|}{ Medicines and commodities } \\
\hline Condoms & 35 (62.1) \\
\hline
\end{tabular}

HTC, HIV Testing and Counselling; STI, Sexually Transmitted Infection.

services was $26.2 \%$. However, $106(14.9 \%)$ of all health facilities had overall percentage readiness scores of $50 \%$ or above, which were defined as ready to provide STI services (data not shown). Figure 1 further presents the readiness score of the four domains and the overall index of health facility readiness to deliver HTC service. The mean readiness score of HTC services was $68.9 \%$. In contrary to STI service readiness, 49 health facilities (85.9\%) had overall percentage readiness scores of $50 \%$ or more and were considered ready to provide HTC services (data not shown). The overall readiness score was found to differ significantly according to the managing authority (private vs public) for both HTC and STI Service Readiness Index. Public sector facilities appeared to be less prepared to deliver STI services compared with private facilities. Interestingly, this was different for HTC services; the public health facilities outscored private health facilities (figure 2).

Factors associated with readiness to provide STI and HTC services In the bivariate and multivariate analysis, readiness of facilities to provide STI services was lower at private and 


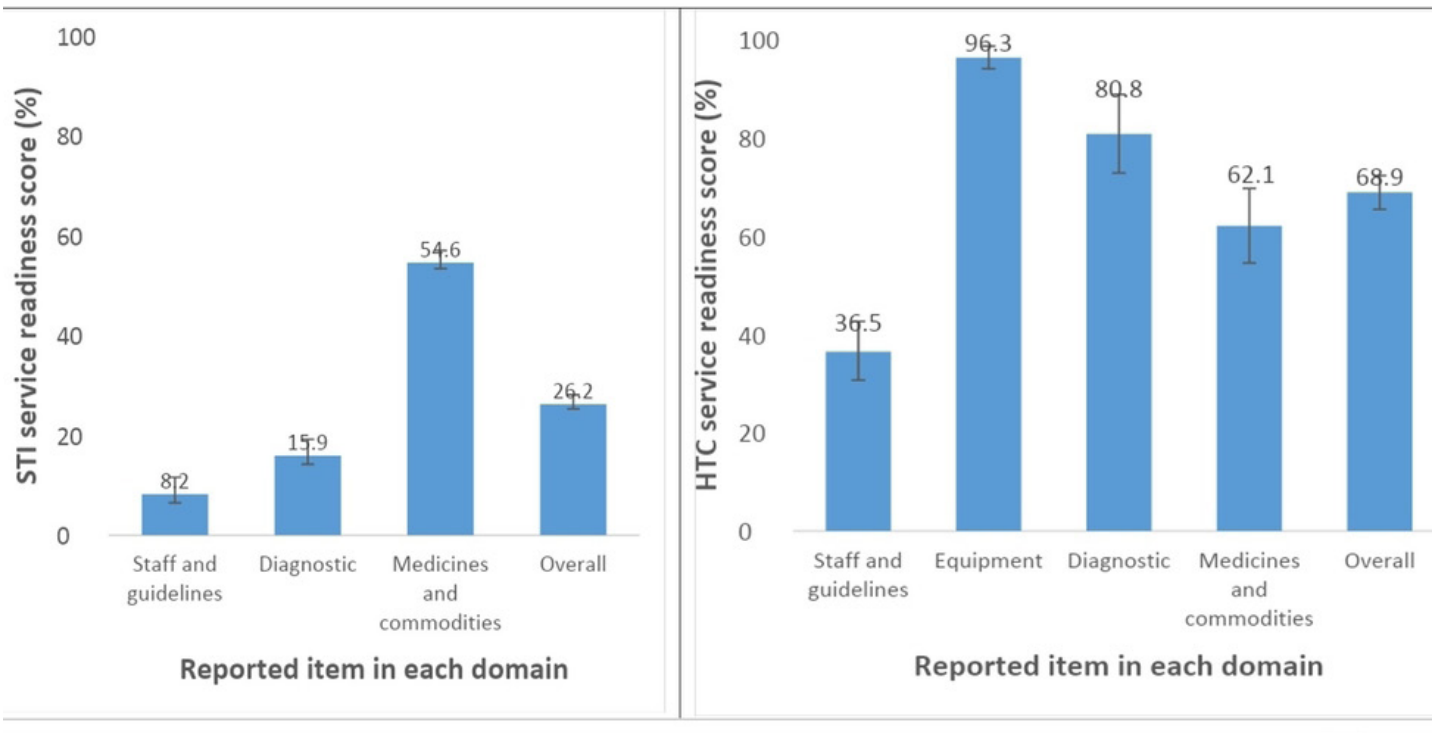

Figure 1 Percentage score of the four domains of readiness to provide sexually transmitted infection and HIV testing and counselling services. HTC, HIV testing and counselling; STI, Sexually Transmitted Infection.

peripheral facilities compared with governmental hospitals. Interestingly, health facilities where external supervision occurred in the last 4 months had better service readiness of STI services compared with those facilities with no external supervision occurred (3.7\% points better than those not occurred). While running the model with all proposed covariates, the estimation routine omits a managing authority, it does so, because of a dependency among other covariates in the model (table 4).

Regarding the multivariate results of HTC services, service readiness was lower at private hospitals $(32.9 \%$ points poorer than government hospitals) and higher at standalone HTC $(8.0 \%$ points better than government hospitals). Unlike STI services, the readiness of facilities

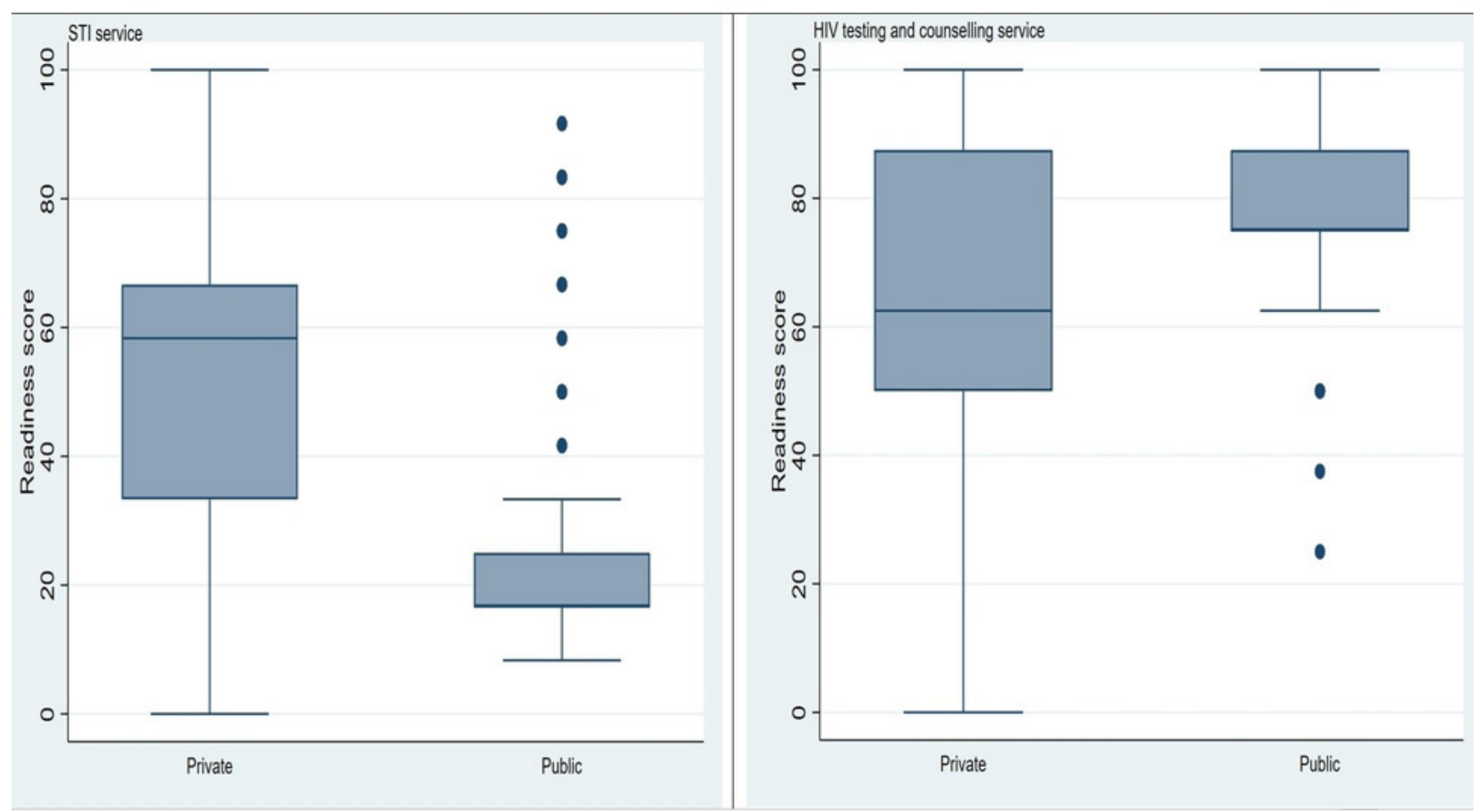

Figure 2 Overall readiness score for sexually transmitted infection and HIV testing and counselling service according to the managing authority. STI, Sexually Transmitted Infection. 
Table 4 Results of unadjusted and adjusted multiple regression models of factors associated with readiness to provide sexually transmitted infection and HIV testing and counselling services

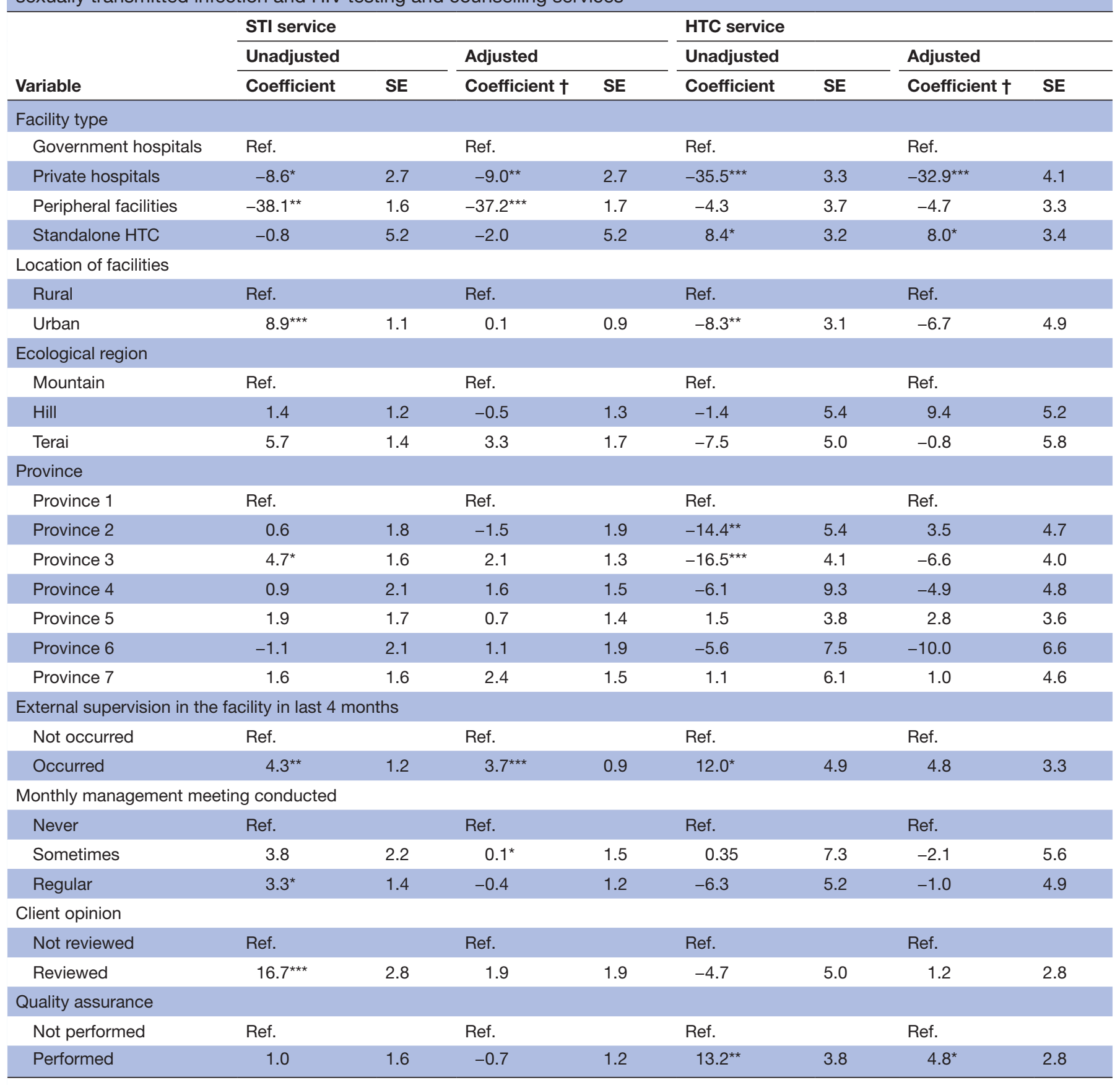

${ }^{*} \mathrm{p}<0.05,{ }^{* *} \mathrm{p}<0.01,{ }^{* * *} \mathrm{p}<0.001$.

†Adjusted coefficient: each variable in the model has been adjusted by all other variables.

HTC, HIV Testing and Counselling; STI, Sexually Transmitted Infection.

to provide HTC services was higher at facilities which performed quality assurance $(4.8 \%$ points better than those not performed) (table 4 ).

\section{DISCUSSION}

Nepal is committed to the global STI strategy to rapidly reduce new sexual infections by 2022. Further, Nepal is aiming to achieve the ambitious target of $90-90-90$ by 2020 and ending the epidemic by 2030 ; thus, it is imperative to understand the country's capacity to deliver high quality HIV and STI services and to track service provision to realise the targets. There is difference between the proportion of the facilities that provide STI services and HTC services. Most notably, nearly all sites providing HTC services were located in the urban regions. This might be due to the reason that STI services are integrated with other health programs such as maternal and neonatal health which has wide coverage and provided through 
all health facilities whereas HTC service is focused to key populations.

Health service delivery without guaranteeing a minimum level of quality is unethical and waste of resources. ${ }^{22}$ Service readiness is a prerequisite to the delivery of quality healthcare. In Nepal, the investigators reported the overall service readiness to be $68 \%$ which is in concurrence to the HIV service readiness; however, STI service readiness appears to be quite low compared with overall service readiness. ${ }^{23}$ This finding and the similar deficits identified in a study of contraceptive and other general health services and overall service readiness raises concern about the general readiness of the health facilities in Nepal. ${ }^{2324}$ We found that the health facilities lacked relevant guidelines, trained staff, diagnostic equipment and medicines to provide STI and HTC services. Aryal $e t a t^{25}$ report the similar gap in health facilities' readiness to provide other health services such as maternal, newborn and FP services. Of particular concern is the low readiness of health facilities for STI services. Despite a large proportion (76\%) of health facilities designated to provide STI services, these facilities were mainly lacking in medicines, diagnosis or operating guidelines, thus, resulting in poor readiness. The current prevalence of STI is around $0.2 \%$ in the general population with the prevalence being markedly high among key populations. ${ }^{8}$ The cases of STIs are increasing every year with more than 140000 cases each year. ${ }^{26}$ Despite, the national strategy to integrate STI services with HIV and ANC services, the lower readiness of facilities to deliver STI services compared with HIV or ANC services indicates that the STI services have not been fully integrated with these services. ${ }^{27}$

In agreement with Acharya and Paudel, ${ }^{23}$ our study reported that the facilities with external supervision performed better than those without regular supervision and monitoring in improving service readiness. ${ }^{11}$ Regular supervision facilitates the management process and improves effectiveness of an organisation. ${ }^{28}$ Such supervision allows information sharing and performance review and is pivotal to improving quality of health services, which might explain better performance among those receiving regular supervision. ${ }^{29}$ In Nepal, such supervision was found to be effective in improving the availability of guidelines or even managing drug stock-outs. Standardised training, certification and ongoing supervision are identified as the crucial element in ensuring the quality at the point-of-care testing. ${ }^{30}$ Factors such as nonadherence to testing procedures, high workload and inadequate supervision were identified as the major factors impeding the delivery of quality HIV testing services in Zambia. ${ }^{31}$ Under the federal management, the management of the peripheral health facilities and the provision of basic health services have been transferred to the local government. ${ }^{32}$ Thus, this study accentuates the role of the local government in regular monitoring while improving the procurement and supply system to scale-up HIV readiness and service provision.

Service readiness varied by the type of ownership and level of facilities. The peripheral health facilities were reported to have inadequate diagnostic facilities and low availability of essential drugs consistent with the findings from a multi-country analysis for seven low-income and middle-income countries. ${ }^{33}$ Most people in rural areas rely on these peripheral health facilities; thus, poor readiness of peripheral health facilities hinders access of such services to those living in rural areas. Public health facilities appeared to perform lower than the private health facilities, although not all private health hospitals fulfilled the criteria for basic amenities, diagnostic capacity and essential medications. Inadequate supply of basic amenities, diagnostic services and medicines in peripheral health facilities and public facilities can exacerbate the growing inequity in health services. Interestingly, HTC services appeared to be better in the public than private sector unlike, maternal and child health services. ${ }^{34}$ On further disaggregation, stand-alone health facilities appear to perform better than private hospitals and public facilities. Often, these standalone sites are run through external partners, offer dedicated HIV services and are target driven with instituted close monitoring systems which might explain the better performance and readiness of these stand-alone facilities.

In Nepal, antiretroviral therapy is provided mainly through public health facilities. Moreover, HTC services including antiretroviral therapy are provided free of charge through these public health facilities; thus, HIVrelated services often are not the service choice for many for-profit private health facilities, which could have potentially enhanced the performance of the public health sites compared with the private sector. ${ }^{26}$

Though the National HIV Testing and Treatment Guideline 2017 outlines that all health facilities providing HTC services irrespective of ownership (public vs private) should strictly adhere to the standard guidelines, not all private hospitals were found to be reporting under Integrated Health Managements Information System and thus, the service standard and services provided through private sector remain underreported.$^{26}$ In an assessment of the safer abortion services readiness, the private sector was found to be low performing, although around half of the safer abortion services are being delivered through private sector. ${ }^{35}$

Stock-out of essential drugs has been a perennial problem in most of the low-income and middle-income countries. ${ }^{36}$ The overall availability of essential medicines ranged from $29.4 \%$ to $54.4 \%$ in many low-income and middle-income countries. ${ }^{37}$ Availability and quality of the services determine the selection and uptake of STI and HIV services. ${ }^{38}$ To improve accuracy of HIV testing, paraprofessionals should receive more standardised HIV rapid testing training and regular supervision. Among the factors affecting the quality of HIV testing; nonadherence to testing procedures, inadequate training and supervision deter the quality of health services. ${ }^{38}$ Less than $10 \%$ of STI service sites and only one-third of HTC service sites had operational guidelines which are taken as a proxy indicator for adherence to testing procedures. 
These persistent deficits and poor readiness of service sites contradict with the spirit of the Nepal Health Sector Strategy Implementation Plan (2015-2020) in ensuring the minimum standard of services.

\section{Strength and limitation}

This is the first study that analysed the nationally representative data and assessed the availability and facility level readiness to provide STI and HTC services in Nepal. The study has some limitations. We analysed the data from the survey conducted 5 years earlier; therefore, the data may not reflect recent developments after the federalised health system in Nepal. However, these are the latest data available on the health facility readiness. A further analysis would be a pooled analysis of the closely timed surveys among households and facilities to explore the association between service readiness and uptake of these services. Further, it should be noted that changes over time in the policy alignments of major supporters with respect to STI and HIV programming may have inclined the levels of readiness observable for the later NHFS surveys.

\section{CONCLUSION}

Conclusively, health facility readiness to deliver services is critical for reaching the SDG target. The mean readiness score of the STI service was $26.2 \%$ and that of HTC service was $68.9 \%$. Service readiness was higher among the government hospitals and facilities with external supervision. Likewise, HTC service readiness was higher at standalone HTC and facilities that performed quality assurance. There are persistent gaps in delivering services for HIV and STI, thus, compromising the standard of care delivered through these sites. Future strategies should be focused on enhancing service readiness through the provision of adequate supplies, adherence to the guidelines and enhancing diagnostic capacities. Local government has a critical role in ensuring the quality and availability of these services. A comparative analysis can be undertaken after the data from the subsequent survey is available.

Acknowledgements The authors would like to acknowledge the DHS programme for permitting us to access the dataset. They thank Ms Kate Killberg for supporting them with the refinement and editing of this paper.

Contributors KA conceptualised and designed the study, performed statistical analysis and wrote them. RT, NB and KB conducted the literature review, involved in the writing the manuscript, edited and revised the manuscript. BS supervised, provided advice and edited the manuscript. All authors read and approved the final manuscript.

Funding The authors have not declared a specific grant for this research from any funding agency in the public, commercial or not-for-profit sectors.

Competing interests None declared.

Patient consent for publication Not required.

Ethics approval The 2015 NHFS in Nepal was reviewed and approved by the Institutional Review Board of Nepal Health Research Council, Nepal; data were publicly available and did not include facility identity. Before interviews were performed, informed consent was obtained from the health workers present at the facility on the day of visit. We have done the secondary analysis of available datasets and thus did not require ethics approval.

Provenance and peer review Not commissioned; externally peer reviewed.

Data availability statement Data are available in a public, open access repository. The datasets generated during the current study are available from within the Demographic and Health Survey Program repository (https://dhsprogram.com/data/ available-datasets.cfm).

Supplemental material This content has been supplied by the author(s). It has not been vetted by BMJ Publishing Group Limited (BMJ) and may not have been peer-reviewed. Any opinions or recommendations discussed are solely those of the author(s) and are not endorsed by BMJ. BMJ disclaims all liability and responsibility arising from any reliance placed on the content. Where the content includes any translated material, BMJ does not warrant the accuracy and reliability of the translations (including but not limited to local regulations, clinical guidelines, terminology, drug names and drug dosages), and is not responsible for any error and/or omissions arising from translation and adaptation or otherwise.

Open access This is an open access article distributed in accordance with the Creative Commons Attribution Non Commercial (CC BY-NC 4.0) license, which permits others to distribute, remix, adapt, build upon this work non-commercially, and license their derivative works on different terms, provided the original work is properly cited, appropriate credit is given, any changes made indicated, and the use is non-commercial. See: http://creativecommons.org/licenses/by-nc/4.0/.

ORCID iD

Kiran Acharya http://orcid.org/0000-0002-7757-0066

\section{REFERENCES}

1 UNAIDS. Global AIDS update. UNAIDS 2019 https://www.unaids.org/ en/resources/documents/2019/2019-global-AIDS-update (Accessed April 2, 2020).

2 UNAIDS. 90-90-90: treatment for all. UNAIDS 2014 https://www. unaids.org/en/resources/909090 (Accessed May 24, 2020).

3 National Centre for AIDS and STD Control. HIV Factsheet. National Centre for AIDS and STD Control 2019 http://www.ncasc.gov.np/ WAD2019/Factsheet2019.pdf

4 Paudel V, Baral KP. Women living with HIV/AIDS (WLHA), battling stigma, discrimination and denial and the role of support groups as a coping strategy: a review of literature. Reprod Health 2015;12:53.

5 Shrestha R, Philip S, Shewade HD, et al. Why don't key populations access HIV testing and counselling centres in Nepal? Findings based on national surveillance survey. BMJ Open 2017;7:e017408.

6 Ministry of Health, Nepal; New ERA; and ICF. Nepal Demographic and Health Survey 2016Nepal: Ministry of Health, 2017.

7 Paudel T, Singh N, Raj Banjara M, et al. Epidemiology of HIV, programmatic progress and gaps in last 10 years in Nepal. $J$ Virus Erad 2016;2:35-40.

8 Shakya S, Thingulstad S, Syversen U, et al. Prevalence of Sexually Transmitted Infections among Married Women in Rural Nepal. In: Cu-Uvin S, ed. Infectious diseases in obstetrics and gynecology. , 2018: 2018, 4980396.

9 National Centre for AIDS and STD Control. National guidelines on case management of sexually transmitted infections. National Centre for AIDS and STD Control 2014

10 Ministry of Health and Population. HIV and STI control programme. Government of Nepal Ministry of Health and Population. Accessed September 13, 2020 https://www.mohp.gov.np/eng/program/ communicable-disease/hiv-sti-control-programme

11 Khatoon S, Budhathoki SS, Bam K, et al. Socio-Demographic characteristics and the utilization of HIV testing and counselling services among the key populations at the Bhutanese refugees camps in eastern Nepal. BMC Res Notes 2018;11:535.

12 Nnko S, Kuringe E, Nyato D, et al. Determinants of access to HIV testing and counselling services among female sex workers in subSaharan Africa: a systematic review. BMC Public Health 2019;19:15.

13 National Centre for AIDS and STD Control. National HIV strategic Plan2016-2021. National Centre for AIDS and STD Control 2017.

14 Bintabara D, Nakamura K, Seino K. Determinants of facility readiness for integration of family planning with HIV testing and counseling services: evidence from the Tanzania service provision assessment survey, 2014-2015. BMC Health Serv Res 2017;17:844.

15 Ministry of Health, Nepal; New ERA, Nepal. Nepal Health Sector Support Program (NHSSP); and ICF. In: Nepal health facility survey 2015. Nepal: Ministry of Health, 2017. 
16 Sheffel A, Karp C, Creanga AA. Use of service provision assessments and service availability and readiness assessments for monitoring quality of maternal and newborn health services in low-income and middle-income countries. BMJ Glob Health 2018;3:e001011.

17 World Health Organization, Organisation for Economic Co-operation and Development, and The World Bank. Service availability and readiness assessment (SARA) an annual monitoring system for service delivery 2015.

18 Acharya K, Paudel YR, Dharel D. The trend of full vaccination coverage in infants and inequalities by wealth quintile and maternal education: analysis from four recent demographic and health surveys in Nepal. BMC Public Health 2019;19:1673.

19 Bintabara D, Ernest A, Mpondo B. Health facility service availability and readiness to provide basic emergency obstetric and newborn care in a low-resource setting: evidence from a Tanzania national survey. BMJ Open 2019;9:e020608.

20 Mallick L, Temsah G, Wang W. Comparing summary measures of quality of care for family planning in Haiti, Malawi, and Tanzania. PLoS One 2019;14:e0217547.

21 Shwartz M, Restuccia JD, Rosen AK. Composite measures of health care provider performance: a description of approaches. Milbank $Q$ 2015;93:788-825.

22 Kruk ME, Gage AD, Arsenault C, et al. High-Quality health systems in the sustainable development goals era: time for a revolution. Lancet Glob Health 2018;6:e1196-252.

23 Acharya K, Paudel YR. General health service readiness and its association with the facility level indicators among primary health care centers and hospitals in Nepal. J Glob Health Rep 2019;3:e2019057.

24 Pant PD. Stagnant modern contraceptive prevalence rate: exploring the reasons and way forward. Presented at the: National Conference on Family Planning. Kathmandu,Nepal, 2019.

25 Aryal K, Dangol R, Gartoulla P, et al. Health services availability and readiness in seven provinces of Nepal further analysis of the 2015 Nepal health facility survey DHS further analysis reports No. 115 government of Nepal Ministry of health and population 2018.

26 Department of Health Services. Annual report 2074/75. Department of Health Services 2018.
27 Kc A, Singh DR, Upadhyaya MK, et al. Quality of care for maternal and newborn health in health facilities in Nepal. Matern Child Health J 2020;24:31-8.

28 Marquez L, Kean L. Making supervision supportive and sustainable: new approaches to old problems, 2002. Available: www.usaidassist. org/sites/default/files/maqno4final.pdf [Accessed Published online]

29 Mwendwa P, McAuliffe E, Ogenna U, et al. The impact of supportive supervision on the implementation of HRM processes; a mixedmethods study in Tanzania. Health Systems and Policy Research 2017;04.

30 World Health Organization, Organisation for Economic Co-operation and Development, and The World Bank. Delivering quality health services: a global imperative for universal health coverage. 2018.

31 Qiao S, Zhang Y, Li X, et al. Facilitators and barriers for HIV-testing in Zambia: a systematic review of multi-level factors. PLoS One 2018;13:e0192327

32 Thapa R, Bam K, Tiwari P, et al. Implementing federalism in the health system of Nepal: opportunities and challenges. Int $J$ Health Policy Manag 2018;8:195-8.

33 Leslie HH, Spiegelman D, Zhou X, et al. Service readiness of health facilities in Bangladesh, Haiti, Kenya, Malawi, Namibia, Nepal, Rwanda, Senegal, Uganda and the United Republic of Tanzania. Bull World Health Organ 2017:95:738-48.

34 Lama TP, Munos MK, Katz J, et al. Assessment of facility and health worker readiness to provide quality antenatal, intrapartum and postpartum care in rural southern Nepal. BMC Health Serv Res 2020;20:16 10.1186/s12913-019-4871-x

35 Bell SO, Zimmerman L, Choi Y, et al. Legal but limited? abortion service availability and readiness assessment in Nepal. Health Policy Plan 2018;33:99-106.

36 Tripathi N, Kerketta F, Chatterjee P, et al. Access and availability of essential medicines in Chhattisgarh: situation in public health facilities. J Family Med Prim Care 2018;7:152-6.

37 Cameron A, Ewen M, Ross-Degnan D, et al. Medicine prices, availability, and affordability in 36 developing and middle-income countries: a secondary analysis. Lancet 2009;373:240-9.

38 Erena AN, Shen G, Lei P. Factors affecting HIV counselling and testing among Ethiopian women aged 15-49. BMC Infect Dis 2019;19:1076. 